\title{
Formulation and Evaluation of a Topical Niosomal Gel Containing a Combination of Benzoyl Peroxide and Tretinoin for Antiacne Activity [Retraction]
}

\author{
Gupta A, Singh S, Kotla N, Webster \\ T. Int J Nanomedicine. 2015;10:171-182.
}

The Publisher and Editor of International Journal of Nanomedicine wish to retract the published article. It came to the journals attention that several images shown in Figure 16 of the article appeared to be duplicated. Specifically,

- The three panels in the top row, Control group (without inducing acne), appears to show duplicated versions of the same image which have been frame shifted and had their size altered.

- The left and right panels of the row, Acne induced group 1, appear to show duplicated versions of the same image with the left panel being an enlarged version of the image on the right.

- The middle panel of the row, Acne induced group 1, and the three panels of the row, Acne induced group 2 , appear to be duplicated versions of the same image which have been frame shifted and undergone size alterations.

- The left and middle panels of the row, Rabbit ear pinna after treatment with cream formulation for 14 days, appear to show duplicated regions of the same image which have been rotated.
- The left panel of the row, Rabbit ear pinna after treatment with cream formulation for 14 days, appears to be duplicated with the image shown in the right panel of the bottom row, Rabbit ear pinna after treatment with niosomal gel formulation for 14 days, but this image has been rotated.

- The left and middle panels of the bottom row, Rabbit ear pinna after treatment with niosomal gel formulation for 14 days, appear to show the same duplicated image with have been rotated and had their size altered.

The authors could not provide a satisfactory explanation for the alleged image manipulation nor could they provide copies of the original images.

Our decision-making was informed by our policy on publishing ethics and integrity and the COPE guidelines on retraction.

The retracted article will remain online to maintain the scholarly record, but it will be digitally watermarked on each page as "Retracted".
The International Journal of Nanomedicine is an international, peerreviewed journal focusing on the application of nanotechnology in diagnostics, therapeutics, and drug delivery systems throughout the biomedical field. This journal is indexed on PubMed Central, MedLine, CAS, SciSearch ${ }^{\mathbb{B}}$, Current Contents ${ }^{\mathbb{B}} /$ Clinical Medicine,
Journal Citation Reports/Science Edition, EMBase, Scopus and the Elsevier Bibliographic databases. The manuscript management system is completely online and includes a very quick and fair peer-review system, which is all easy to use. Visit http://www.dovepress.com/ testimonials.php to read real quotes from published authors. 